\title{
Letter \\ Nucleus pulposus cells as competent phagocytes to clear apoptotic cells: mission applicable or impossible?
}

\author{
Hai-Oiang Wang and Zhuo-Jing Luo
}

Institute of Orthopaedics, Xijing Hospital, \#17 Changle Western Road, Fourth Military Medical University, Xi'an 710032, People's Republic of China

Corresponding author: Zhuo-Jing Luo, zjluo@fmmu.edu.cn

Published: 6 May 2009

This article is online at http://arthritis-research.com/content/11/3/405

(c) 2009 BioMed Central Ltd
Arthritis Research \& Therapy 2009, 11:405 (doi:10.1186/ar2647)

See related research by Jones et al., http://arthritis-research.com/content/10/4/R86 and related letter by Jones et al., http://arthritis-research.com/content/11/3/406

We have read with interest the research article by Philip Jones and colleagues, in which they studied whether bovine nucleus pulposus (NP) cells were capable of behaving as phagocytes [1]. Collectively, they drew the conclusion that disc cells clearly can undergo phagocytosis, which has implications for the intervertebral disc in vivo. We would like to differ from the authors, however, regarding the implications of the role of NP cells in vivo in comparison with in vitro as competent phagocytes to ingest apoptotic cells.

First, NP cells cultured in vitro in a monolayer may not reflect the same physiological status as they showed in vivo. In fact, the extracellular matrix of NP cells consists largely of water, collagen type II and aggrecan [2]. The cell concentration within the disc is relatively sparse, making up only about $1 \%$ of the disc volume. NP cells in vivo therefore distribute sparsely in the intervertebral disc with ample extracellular matrix surrounding. Intercellular communications might pointedly differ from those in cell culture conditions, in which NP cells contact directly and closely. From this point of view, it may appear an impossible mission for NP cells to clear apoptotic cells as phagocytes in vivo.

Second, the authors might have omitted one important hallmark of NP cells - that is, immune privilege. In fact, there is accumulating evidence demonstrating that Fas ligand (CD178) is highly expressed in human, rat and rabbit normal NP cells [3,4]. In immune privileged organs, Fas ligand has been shown to act via the induction of apoptosis on invading Fas-positive activated T cells and thus protects the cells from immune attack. The question of whether macrophages take part in the interaction of NP cells with Fas ligand and consequently contribute to clearance of apoptotic cells, however, remains open. Whether the death of NP cells occurs by apoptosis or necroptosis also remains unclear [5]. At present, therefore, we may not exclude macrophages perhaps playing a role in the clearance of apoptotic cells.

Third, despite the special avascular hallmark of intervertebral discs, cells in the center of the disc exist at low concentrations of oxygen. Oxygen concentrations as low as 1\% have been measured in the centers of discs [6]. The oxygen concentration in Jones and colleagues' paper was $21 \%$, however, which may not be consistent with the physiological conditions of NP cells. As a consequence, the conclusion the authors made on the basis of altered oxygen concentration and the subsequently changed cellular physiology may not be reliable.

Taking these points together, a more appropriate NP cell culture system and the role of macrophages in immune privilege of NP cells should be further explored.

\section{Competing interests}

The authors declare that they have no competing interests.

\section{References}

1. Jones P, Gardner L, Menage J, Williams G, Roberts S: Intervertebral disc cells as competent phagocytes in vitro: implications for cell death in disc degeneration. Arthritis Res Ther 2008, 10:R86.

2. Hunter CJ, Matyas JR, Duncan NA: The notochordal cell in the nucleus pulposus: a review in the context of tissue engineering. Tissue Eng 2003, 9:667-677.

3. Takada T, Nishida K, Doita M, Kurosaka M: Fas ligand exists on intervertebral disc cells: a potential molecular mechanism for immune privilege of the disc. Spine 2002, 27:1526-1530.

4. Kaneyama S, Nishida K, Takada T, Suzuki T, Shimomura T, Maeno $\mathrm{K}$, Kurosaka M, Doita M: Fas ligand expression on human nucleus pulposus cells decreases with disc degeneration processes. J Orthop Sci 2008, 13:130-135.

5. Hitomi J, Christofferson DE, Ng A, Yao J, Degterev A, Xavier RJ, Yuan J: Identification of a molecular signaling network that regulates a cellular necrotic cell death pathway. Cell 2008, 135:1311-1323.

6. Bartels EM, Fairbank JCT, Winlove CP, Urban JPG: Oxygen and lactate concentrations measured in vivo in the intervertebral discs of patients with scoliosis and back pain. Spine 1998, 23:1-7. 